\title{
A Dynamic Model for Assessing the Effects of Construction Workers' Waste Behavior to Reduce Material Waste
}

\author{
Herlina Suciati"*, Tri Joko Wahyu Adi ${ }^{\#}$, I Putu Artama Wiguna ${ }^{\#}$ \\ ${ }^{\#}$ Faculty of Civil Engineering, Institute Teknologi Sepuluh Nopember, Surabaya, Indonesia \\ E-mail:hsuciati76@gmail.com,trijokowahyuadi@gmail.com,artama.wiguna@gmail.com \\ *Faculty of Civil Engineering, Batam University, Batam, Indonesia \\ *Email: hsuciati76@gmail.com
}

\begin{abstract}
Construction waste has become a pressing issue in many developing countries and has adverse effect on environment, economic and social aspects. The construction industry in Indonesia characterized by the use of the human resources that are more intensive compared to the use of technology. The high use of human resources in the construction industry caused human factor plays an important role an effort to reduce construction waste. As a result, the behavior of construction workers indicated very influentially to the material waste generate from the construction project. The purpose of this research is to determine the relationship between the waste behavior of construction workers toward waste and its effects on material waste reduction. Research variables that affected the waste behavior of construction workers are obtained from the literature review on the previous studies. A dynamic system model used to describe relationships between variables that affected the waste behavior of construction workers and simulate their effects on material waste reduction. Survey respondents verify causal model between variables. The survey models are an interview and a questionnaire survey. It is intended that all variables used and established relationships in the model may represent a real system in the field and to provide an accurate result. Simulation on the basic model is shown the result that the change of waste behavior of construction workers can reduce material waste by $13.30 \%$ of the total material waste. The results of the simulation and scenario of the model presented that the organizational management has the highest influence on the material waste reduction due to the changing of workers' waste behavior, which is $\mathbf{3 4 . 5 8 \%}$ higher than the base model, and followed by personal factor, organizational culture, and attitudes variables.
\end{abstract}

Keywords - waste behavior; material waste; construction worker; system dynamic

\section{INTRODUCTION}

The construction industry is playing an important role in every developing country. In Indonesia, the growth of the construction industry in 2015 reaches $6.65 \%$ [1]. The construction project will certainly not be separated from the waste generated from the construction activities. In the construction industry, waste defined as any unwanted material [2].

It is widely acknowledged that construction activities generated a huge amount of waste. Research indicates that construction waste is an important problem in the construction industry because of its environmental impacts and its effect on project efficiency [3]. As the results, it affected project performance and productivity. The huge amount of construction waste not only consumes landfill areas but also can cause some irreparable and irreversible impact to the environment including air pollution, water pollution and land pollution [4], [5]. Human health and welfare can be affected by this material waste, especially for all the workers and the residents near the project sites [4].

There are two groups construction waste, physical and non-physical waste [6]. Non-physical waste normally occurs during the construction phase. Non-physical waste is time and cost overrun for construction projects. In general, materials waste or physical waste is defined as waste arises from construction, renovation and demolition activities as solid waste for example sand, bricks, blocks, steel, concrete debris, tiles, bamboo, plastic, glass, wood, and paper [5], [6]. This type of waste consists of a complete loss of materials, due to the fact that they are irreparable damage or simply lost [6].

Several previous studies have been conducted to define the main sources of construction waste. A study of factors contributing to physical and non-physical waste resulted in seven significant factors, i.e., handling, workers, management, field conditions, procurement and external factors [6]. Reference [2] shows that the emergence of waste in building construction projects related purchase on 
materials contrary to specification, inappropriate storage and lack of knowledge and experience in construction waste.

One way to reduce material waste is to apply construction waste management at a construction project. Another study directed to the awareness of construction waste management and factors that affected it on construction projects. The result affirmed that one of the main responsibilities in waste management is to determine strategies that can raise awareness of the workers' behavior of building construction [7].

Like other developing countries, the construction industry in Indonesia has a more intensive use of human resources than the use of technology. The rapid growth of the construction industry in Indonesia directly influences the high absorption of human resources in the construction sector. This makes the construction projects in Indonesia not only affected by material factors, tools, and methodology of construction but also strongly influenced by labor or worker factors.

In an effort to minimize material waste, human resources incidentally are very important. Human resources are one of the main instrument in the organization to achieve the goal of the organization. This causes the quality of human resources to be one of the determinants of the success of a project. A research conducted in Surabaya is shown that the low quality of human resources gave an effect of $59.3 \%$ on the performance of the project [8].

One of the keys to successful implementation of construction waste management depends on the participation of all parties involved in the project, including the construction workers [9], [10]. Yet, workers' waste behavior toward material waste found to be one of the strains in construction waste management implementation in the construction project [11]. Workers' behavior such as lack of awareness of material waste that may arise during the work process is one of the causes of material waste [6]. Construction workers' awareness and behavior on environmental issues could improve worker performance toward material waste and waste can be prevented or reduced by changing workers' behavior [11]. Therefore, effective implementation of construction waste management requires understanding the influencing factors of behavior towards waste and the relationship between these factors as well [12].

The above studies only underline the significance of worker's factors as one of the resources in the construction project and the importance of workers' behavior in an effort to reduce construction waste through the implementation of construction waste management. However, these studies have not explained the factors that influence the behavioral changes themselves and its effects on construction waste reduction.

A theory of planned behavior (TPB) states that a person's behavior is affected by the attitude, subjective norms and behavioral controls that the person receives [13]. In general, the more favorable attitude and subjective norm with respect to a behavior, and the greater perceived behavioral control of performing a specific behavior, the stronger should be an individual's intention to execute the behavior. Given a sufficient degree of behavioral control, individuals are capable of setting their intentions into practice [14].
A research about workers behavior, toward safety, used two main variables the company factors (safety climate ex. management commitment, management system and procedure) and personal factors (personal experience ex. education and work experience, knowledge and attitude). The model constructed using the Bayesian (BN) network. The results of the developed model show that the company factors (safety climate) have a more significant effect on changes in worker's behavior than the personal experience of the worker [15].

A study of construction workers' behavior towards construction waste management in the construction process influenced by two factors, which are personal factors of the workers and company factors [16]. This study used a Bayesian method in which described the influence of each factor on changing workers' behavior, but the research has not shown the relationship of interrelationship and the feedback between each of these factors to change workers' behavior. A framework for changes in the behavior of workers toward waste and environmental issues is developed by a research. The framework influenced by organizational culture factors and workers' attitudes [17]. The framework shows factors that influence the changing of workers' behavior were related to each other, but the factors used in this study are still very limited while there are still other factors that are not examined such as worker's educational level and experiences. Using the previous framework, another research conducted and improved it by adding external factors such as government policy and working group factors [18]. Nevertheless, all the variables in the model are individual, independent and did not interconnect with each other.

Another research proposed a dynamic model of waste reduction in line with various waste management strategies on construction waste reduction. The research used three main scenarios, which are enhancing the efficiency in waste management regulation, increasing investment in waste management and increasing waste landfill charge. The result shows that increasing waste landfill charge has the highest impact of construction waste reduction followed by enhancing the efficiency of waste management regulation [19]. A Study of waste reduction in the construction field with workers' behavior as one of its variables was also conducted by using a dynamic system. The study found a $27.05 \%$ increase in building performance results from waste source reduction while sorting behavior can increase recycling and reuse rates in construction projects, where recycling and reuse contribute $15.49 \%$ of the total waste construction [20]. The simulation shows the existence of interrelationship and the feedback loop between the factors studied. But this study also has not focused on the factors that affected the behavior of the construction workers themselves.

Based on the above description it is seen that not many studies that emphasize the relationship or influence of workers' waste behavior on material waste, as well as the relationship of mutual influence between the factors that shape the workers' waste behavior. While the behavior of construction workers plays an important role in the success of a project so it is important to be able to predict workers' waste behavior based on factors that can influence the 
behavior in an effort to reduce material waste. In short, the identification of factors that influence the waste behavior of construction worker regarding material waste reduction, as well as the quantification of the relationship between respective factors, are imperative towards waste construction minimization.

Therefore, this research focuses on knowing the relationship between factors affecting the waste behavior of construction workers, identifying the feedback influence between those factors and its effect on material waste reduction. From literature review deliberated above, the research positioning of this research shows in Fig. 1. The approach used in this research is a dynamic system model. This is because a dynamic system modeling is suitable to simulate systems that have dynamic and complex characteristics.

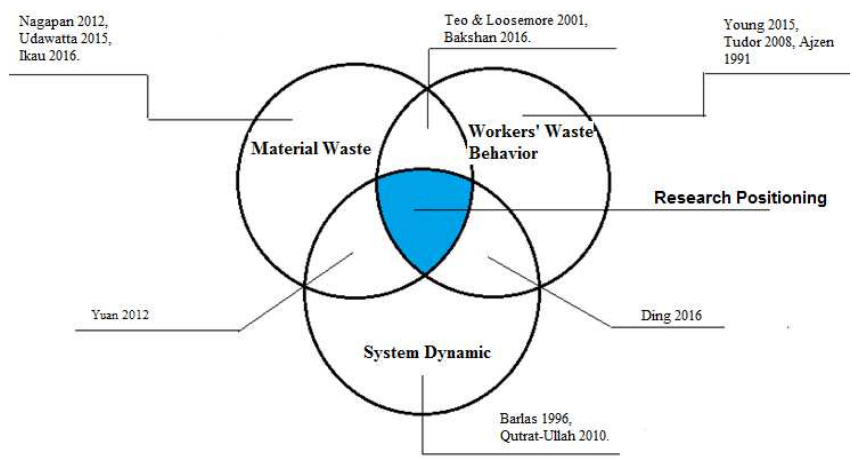

Fig. 1 Research positioning

\section{MATERIAL AND METHOD}

\section{A. Data Collection}

A comprehensive literature review of previous studies was conducted to identify possible variables that might have affected workers' behavior toward material waste minimization. After variables were defined, a survey and deep interview were directed to the expert such as project manager to verify the variables and to validate the relationship between variables. List of variables defined from literature review is shown in Table 1. After all variables and model were constructed, a survey questionnaire was carried out to understand and evaluated the perceptions of construction project workers toward material waste. The construction project workers, who are defined as laborers and supervisors, are the focus of this research because commonly they have the most direct physical contact with the material being wasted and their attitudes have a direct and immediate impact on its efficiency. The questionnaire was prepared based on the Likert scale with the five-point scale ranging from "strongly agree', "agree", "neither agree or disagree", "disagree", to "strongly disagree". Data gathering through the questionnaire was analysed using dynamic system model.

TABLE I

VARIABLE INFLUENCING WORKER WASTE BEHAVIOR TOWARD MATERIAL WASTE REDUCTION

\begin{tabular}{|l|l|l|}
\hline \multicolumn{1}{|c|}{ Variable } & \multicolumn{1}{|c|}{ Sub Variable } & \multicolumn{1}{c|}{ Reference } \\
\hline Attitudes & Attitudes toward behavior (ATB) & {$[20]$} \\
\hline & Environmental attitudes (EAT) & {$[17],[18]$} \\
\hline & Environmental awareness (EAW) & {$[17],[18]$} \\
\hline & Beliefs (BLF) & {$[17]$} \\
\hline Organizational Culture & Group dynamic (GD) & {$[17]$} \\
\hline & Motivation (MTV) & {$[17]$} \\
\hline & Job satisfaction (JS) & {$[17]$} \\
\hline & Financial incentives (FI) & {$[11],[18]$} \\
\hline & Feedback (FB) & {$[18]$} \\
\hline & Supervision (SPV) & {$[16]$} \\
\hline & Management support (MS) & {$[11],[17],[18]$} \\
\hline management & Training (TRN) & {$[11],[16],[17],[18]$} \\
\hline & Company type and size (CTS) & {$[17]$} \\
\hline & Organization focus and policy (OF) & {$[18]$} \\
\hline & Environmental infrastructure (EI) & {$[18]$} \\
\hline Personal factor & Knowledge (KNW) & {$[15]$} \\
\hline & Ages & {$[17]$} \\
\hline & Education (EDC) & {$[15]$} \\
\hline & Work experiences (WE) & {$[16],[15]$} \\
\hline & Awareness toward consequences (ATC) & {$[16]$} \\
\hline & Perceived behaviors control (PBC) & {$[20]$} \\
\hline & Social pressure (SP) & {$[16]$} \\
\hline & Environmental action at home (EAH) & {$[17],[18]$} \\
\hline & Policy and economic context (PEC) & {$[18]$} \\
\hline & & \\
\hline & & \\
\hline & &
\end{tabular}




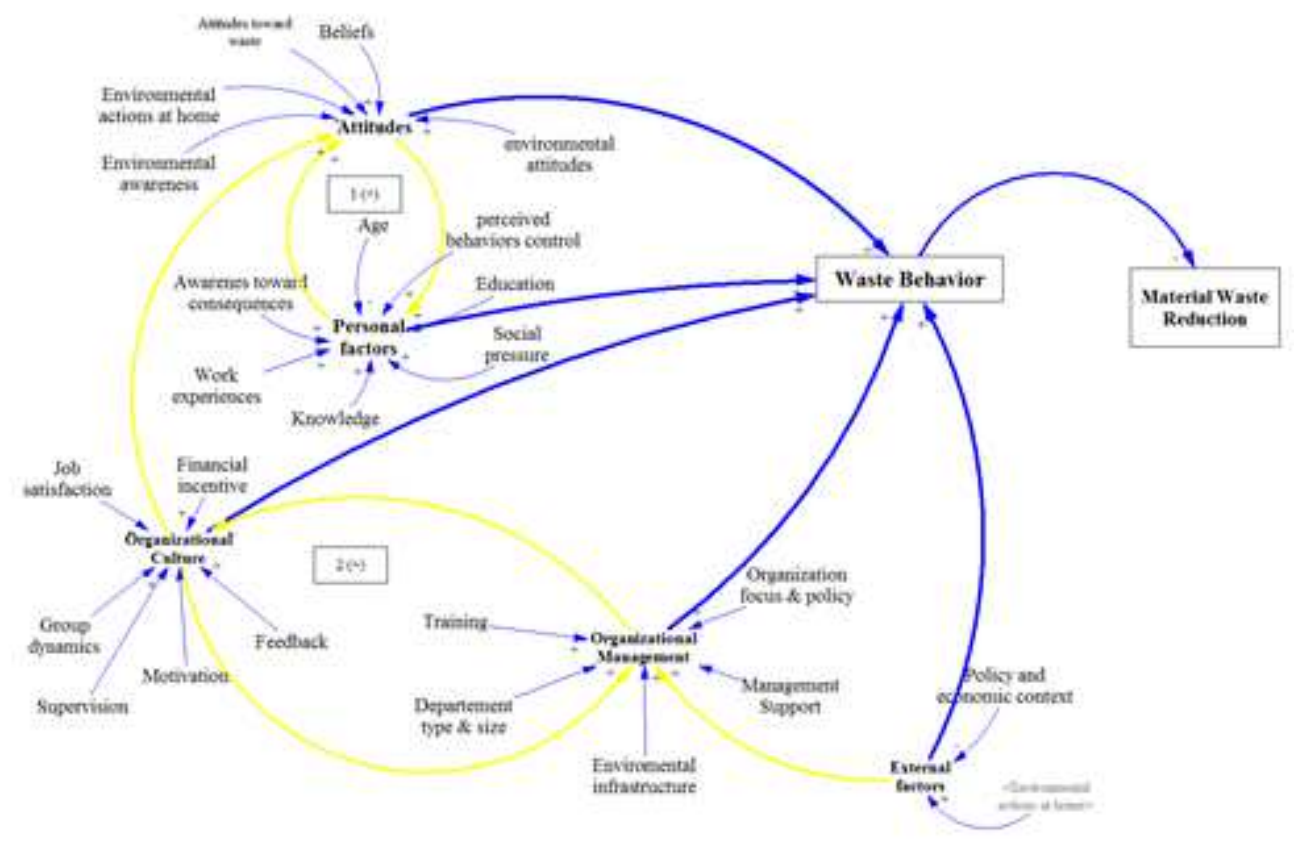

Fig. 2 Causal loop diagram

\section{B. System Dynamics Methodology}

The model proposed in this research is constructed with the principle of system dynamic (SD). SD is a method originated by Jay Forrester (1958), which is a wellestablished methodology for understanding, visualizing and analyzing complex dynamic feedback system [21]. The basic principle of SD is to understand how the main objects within a specific system interact with each other. Hence, the purpose of applying SD is to facilitate understanding of the relationship between the behavior of a system over time and its underlying structure and decision rules [22]. In general, the structure of SD model is represented by causal loop diagram (CLD), which captures the major feedback mechanism. The CLD shows how the system is dynamically affected by the interaction of all variables.

The dynamic behavior of the model is determined by a feedback loop in the CLD. Fig. 2. is shown the CLD of variables that affected workers' behavior toward material waste minimization. Two causal loops are presented, and all the two loops are positive.

Considering the positive feedback loop 1, a change in any variables within the causal loop will eventually affect itself in a positive way. For example, an increase of workers' personal factor (e.g., higher education level) will affect the workers' attitude factor toward waste reduction. The same logic is applied to the feedback loops 2. Based on the CLD, all the variables that affected workers' behavior toward material waste reduction are identified. The conceptual of CLD is then converted to a stock-flow diagram (SFD) using STELLA software, which is shown in Fig. 3

\section{Model Validation}

To ensure that the accuracy of the model can reflect the actual environment, the validity of the SD model needs to be tested. Several tests are used for structural validation of an
SD model i.e. structure verification test, dimension consistency test, parameter verification boundary adequacy test and sensitivity test [21], [22].

1) Structure Verification Test: The persistence of this test is to observe whether the model structure is consistent with relevant descriptive knowledge of the system being modelled [21], [22].

TABLE II

PARAMETER VALUE

\begin{tabular}{|c|c|c|c|}
\hline Variables & Value & Unit & Sources \\
\hline Waste generated index & 0.17 & $\operatorname{ton} / \mathrm{m}^{2}$ & Case Study \\
\hline $\begin{array}{l}\text { Behavior rate of total } \\
\text { waste generated }\end{array}$ & 0.1549 & - & {$[20]$} \\
\hline Parameter value of MS & 0.197 & - & $\begin{array}{l}\text { Survey - } \\
\text { Questionnaire }\end{array}$ \\
\hline $\begin{array}{l}\text { Parameter value of } \\
\text { TRN }\end{array}$ & 0.200 & - & $\begin{array}{l}\text { Survey - } \\
\text { Questionnaire }\end{array}$ \\
\hline $\begin{array}{l}\text { Parameter value of } \\
\text { MTV }\end{array}$ & 0.168 & - & $\begin{array}{l}\text { Survey - } \\
\text { Questionnaire }\end{array}$ \\
\hline Parameter value of FI & 0.172 & - & $\begin{array}{l}\text { Survey - } \\
\text { Questionnaire }\end{array}$ \\
\hline Parameter value of SPV & 0.189 & - & $\begin{array}{l}\text { Survey - } \\
\text { Questionnaire }\end{array}$ \\
\hline $\begin{array}{l}\text { Parameter value of } \\
\text { KNW }\end{array}$ & 0.145 & - & $\begin{array}{l}\text { Survey - } \\
\text { Questionnaire }\end{array}$ \\
\hline Parameter value of Age & 0.128 & - & $\begin{array}{l}\text { Survey - } \\
\text { Questionnaire }\end{array}$ \\
\hline $\begin{array}{l}\text { Parameter value of } \\
\text { EDC }\end{array}$ & 0.137 & - & $\begin{array}{l}\text { Survey - } \\
\text { Questionnaire }\end{array}$ \\
\hline Parameter value of WE & 0.166 & - & $\begin{array}{l}\text { Survey - } \\
\text { Questionnaire }\end{array}$ \\
\hline Parameter value of JS & 0.148 & - & $\begin{array}{l}\text { Survey - } \\
\text { Questionnaire }\end{array}$ \\
\hline $\begin{array}{l}\text { Parameter value of } \\
\text { EAH }\end{array}$ & 0.190 & - & $\begin{array}{l}\text { Survey - } \\
\text { Questionnaire }\end{array}$ \\
\hline
\end{tabular}




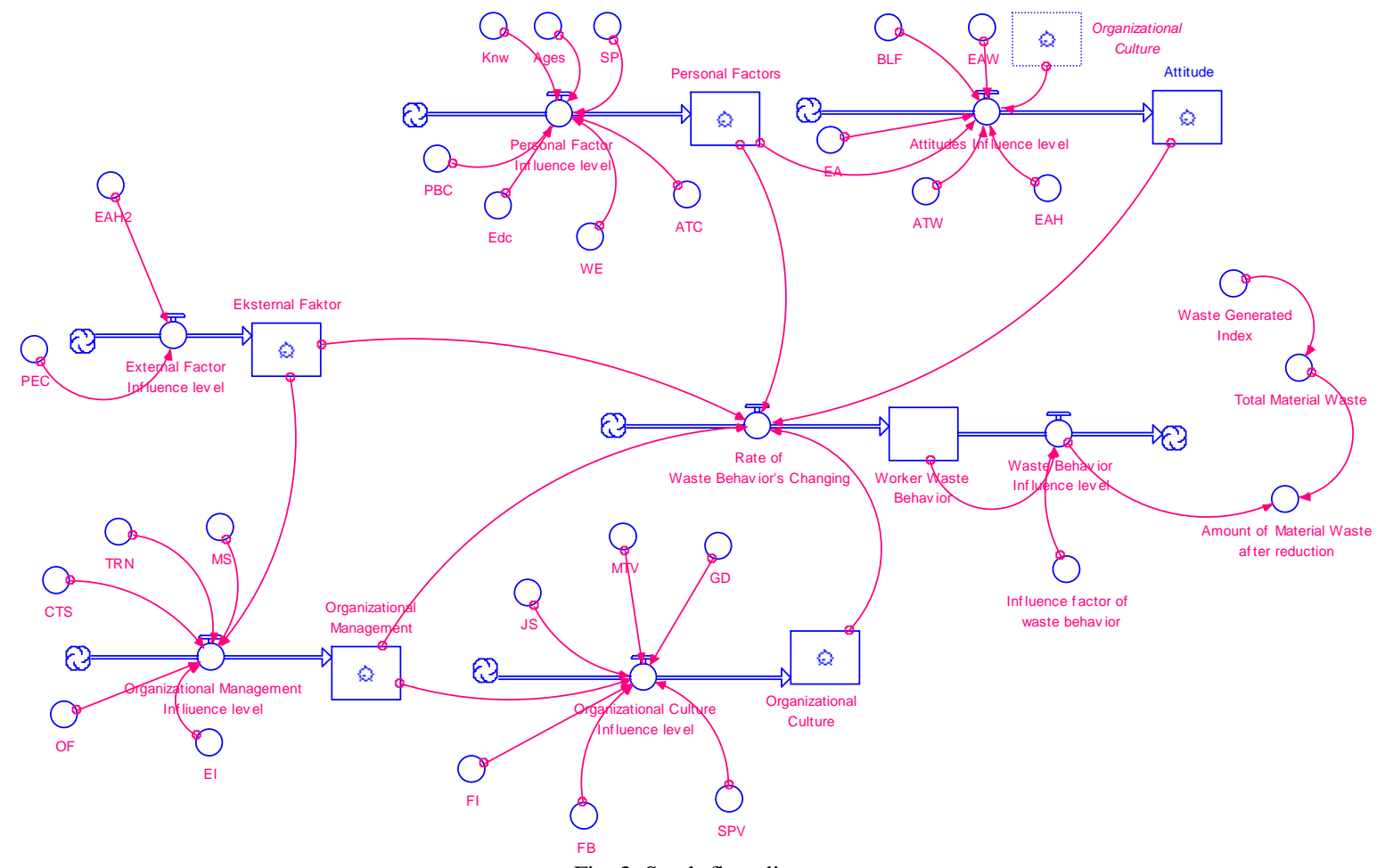

Fig. 3 Stock-flow diagram

The information included in the structure and all-cause and effect chain of the SFD is based on a comprehensive literature review and from an interview with experts that have more than 10 years of experiences in the construction project. Hence, the model structure is logical and closely represents the actual system in construction industry. Stella software has a function for automatically verify the structure and effect chain of the SFD model, Fig. 4. is shown the result of the test.

2) Parameter Verification Test: The intention of this test is to check if the parameter values are consistent with relevant descriptive and numerical knowledge of the system. It is also to observe whether all parameters have a real-world counterpart or not [21], [22]. The parameter values of the proposed model are taken from the literature review and survey questionnaire. Table 2 . shows the parameter values and sources. All the parameters have empirical and theoretical based.

3) Boundary - Adequacy Test: There are three purposes of this test, which are: 1) Are the important concepts in addressing the problem endogenous to the model? 2) Does the behavior of the model change extremely when boundary assumptions are relaxed? 3) Do the policy recommendations change when the model boundary is extended? [21], [22]. All the variables in the SD model proposed have been observed, and it is found that each of this variable is

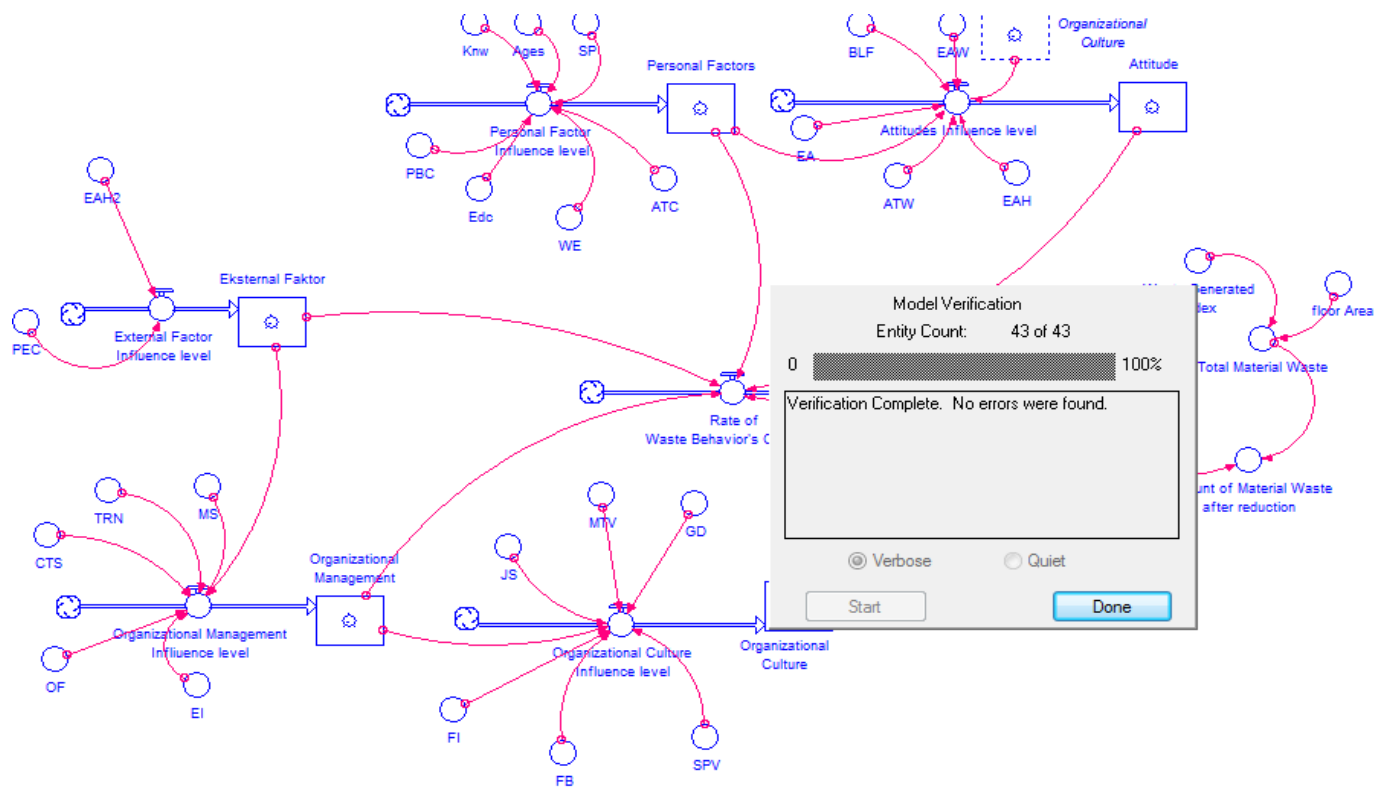

Fig. 4 Model verification test 


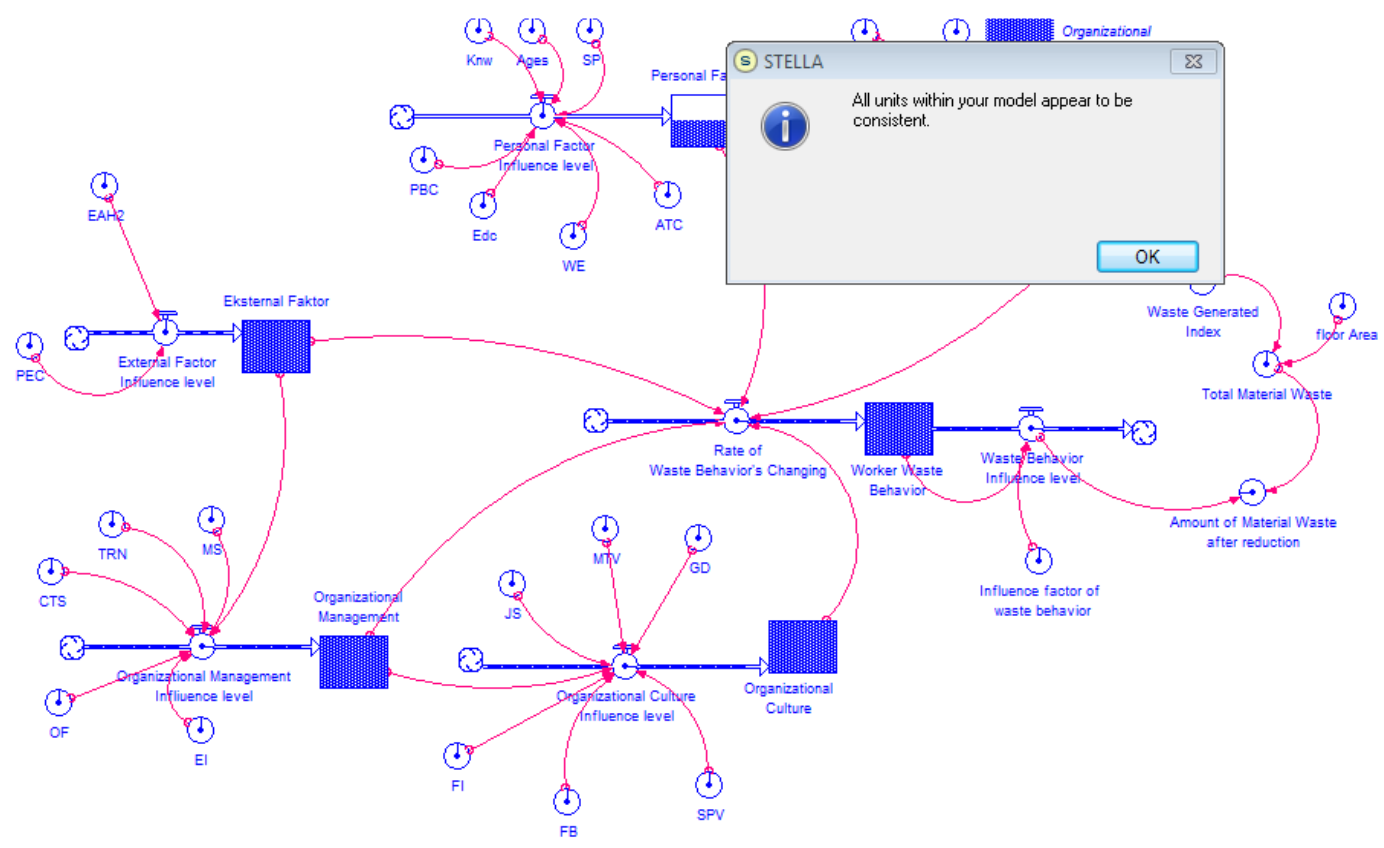

Fig. 5 Dimension consistency test

essential in the research proposed for assessing the behavior of construction workers in reducing material waste.

4) Sensitivity Test: This test was suggested as a behavior validity test to detect major structural flaws of the model, despite the fact that model can generate accurate behavior patterns [21], [22]. An example exemplifying the sensitivity test is used to show the relationship between organizational management (CM) and workers' behavior by adding the percentage of management influence factor, varied from 0 , $25,50,75$ and 100 . The results demonstrate that sensitivity test is relevant and verified as shown in Fig. 6. The test indicates that the trend of the model remains the same and changes only on the numerical results.

5) Absolute Percentage Error (APE): The aim of this test is to measure the accuracy of the model by comparing model prediction results with data from the case study. If the value of APE $\leqslant 30$, then the prediction model is accurate [23]. Below is the formula of APE:

$$
\mathrm{APE}=((\mathrm{yt}-\hat{y t})) / \mathrm{yt} \times 100 \%
$$

Where yt is the actual value for the time period $t$, and $\hat{y} t$ is the forecast value for the time period $t$. The APE for this test is $14.14 \%$, so the model purposed in this research is accurate.

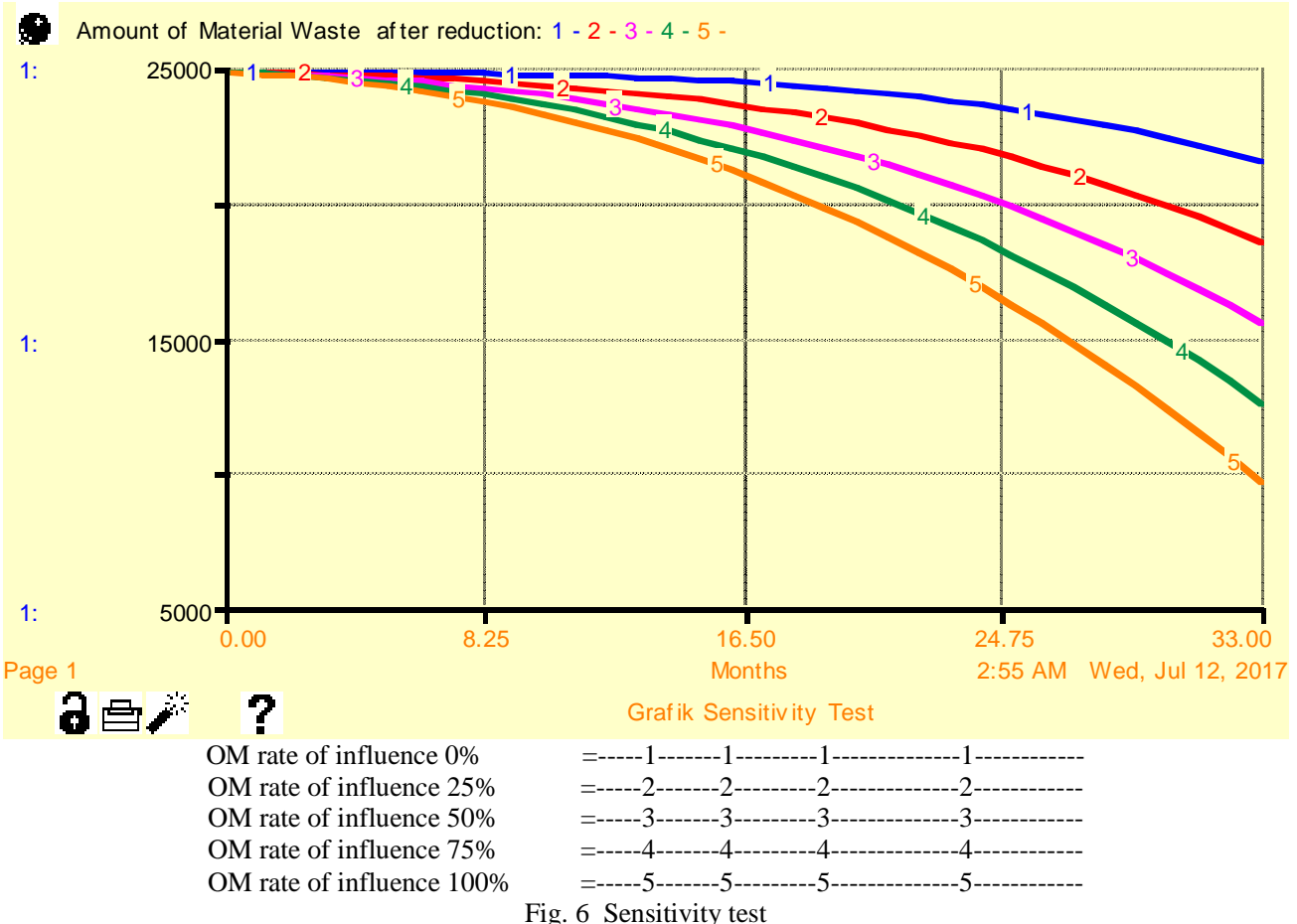




\section{RESULTS AND DISCUSSION}

\section{A. Model Simulation}

A case study was carried out from a construction project in Surabaya. The project selected is a commercial building with gross floor area about $146,515 \mathrm{~m}^{2}$, and the project duration was 33 months. Model duration set as 33 months based on the project reviewed and the waste generated from project divided by gross floor is used as initial value for waste generated index [24]. The waste generated index from case study is 0.17 . Fig. 7 and Table 3 . are shown simulation result from the based model. It shows that material waste reduction is increasing along with the improvement of workers' waste behavior. At the end of the construction period, the amount of waste material reduction reaches $3,312.70$ tons or about $13.30 \%$ of the total material waste.

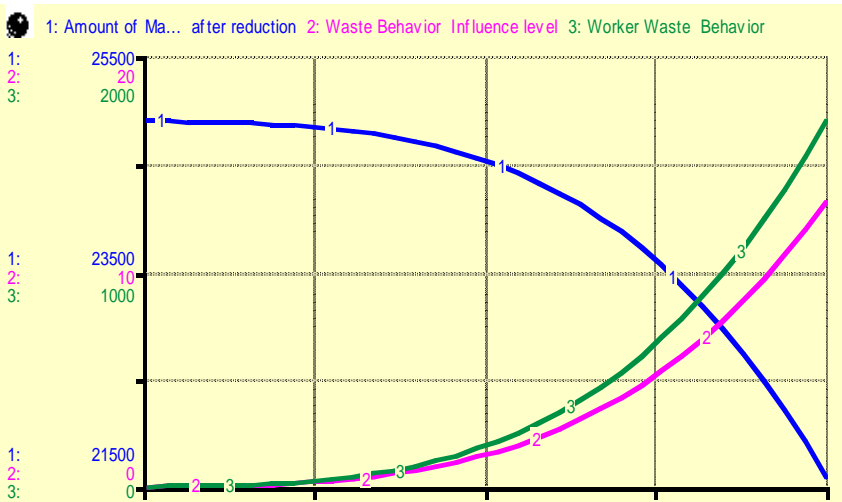

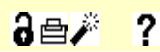

TABLE III

MATERIAL WASTE REDUCTION FROM BASE MOdEL SiMULATION

\begin{tabular}{|c|c|c|c|c|c|}
\hline Month & Material Waste (ton) & $\begin{array}{l}\text { Material Waste } \\
\text { Reduction (ton) }\end{array}$ & Month & Material Waste (ton) & $\begin{array}{l}\text { Material Waste } \\
\text { Reduction (ton) }\end{array}$ \\
\hline 0 & $24,907.55$ & 0.00 & 17 & $24,500.15$ & 407.40 \\
\hline 1 & $24,907.35$ & 0.20 & 18 & $24,423.58$ & 483.97 \\
\hline 2 & $24,906.11$ & 1.44 & 19 & $24,337.10$ & 570.45 \\
\hline 3 & $24,903.53$ & 4.02 & 20 & $24,239.92$ & 667.63 \\
\hline 4 & $24,899.33$ & 8.22 & 21 & $24,131.24$ & 776.31 \\
\hline 5 & $24,893.16$ & 14.39 & 22 & $24,010.19$ & 897.36 \\
\hline 6 & $24,884.66$ & 22.89 & 23 & $23,875.92$ & $1,031.63$ \\
\hline 7 & $24,873.41$ & 34.14 & 24 & $23,727.53$ & $1,180.02$ \\
\hline 8 & $24,859.00$ & 48.55 & 25 & $23,564.08$ & $1,343.47$ \\
\hline 9 & $24,840.94$ & 66.61 & 26 & $23,384.63$ & $1,522.92$ \\
\hline 10 & $24,818.77$ & 88.78 & 27 & $23,188.20$ & $1,719.35$ \\
\hline 11 & $24,791.94$ & 115.61 & 28 & $22,973.79$ & $1,933.76$ \\
\hline 12 & $24,759.90$ & 147.65 & 29 & $22,740.35$ & $2,167.20$ \\
\hline 13 & $24,722.07$ & 185.48 & 30 & $22,486.84$ & $2,420.71$ \\
\hline 14 & $24,677.84$ & 229.71 & 31 & $22,212.16$ & $2,695.39$ \\
\hline 15 & $24,626.56$ & 280.99 & 32 & $21,915.21$ & $2,992.34$ \\
\hline 16 & $24,567.57$ & 339.98 & 33 (Final) & $21,594.85$ & $3,312.70$ \\
\hline
\end{tabular}

\section{B. Scenario}

Scenario conducted in this research is a parameter scenario. Four variables of research used in the scenario, which are attitude, organizational management, organizational culture and personal factor. The scenario conducted by raising the attribute values of the variable by $100 \%$. The purpose of this scenario is to find out the most significant variables of material waste reduction through the changes in the waste behavior of construction workers. The goal is that companies can focus on improving at one of these variables. Table 4 . and Fig. 8 are shown the simulation results in the parameter scenario.

\section{Results Analysis}

In scenario-1, the amount of material waste reduction is $3,779.39$ tons or $15.25 \%$ of the total material waste. Scenario-1 provides reduction result of 1.15 times higher than the base model. In scenario-2, the amount of material waste reduction is $5,134.95$ tons or $20.62 \%$ of the total material waste. Scenario- 2 provides 1.55 times higher of reduction result than the base model. In scenario-3, the amount of material waste reduction is $15,326.44$ tons or
$61.53 \%$ of the total material waste. Scenario-3 provides 4.63 times higher reduction result than the base model. While in scenario-4, the amount of material waste reduction is $5,837.70$ ton or $23.44 \%$ of the total material waste. Scenario- 4 provides a higher reduction result of 1.76 times than the base model.

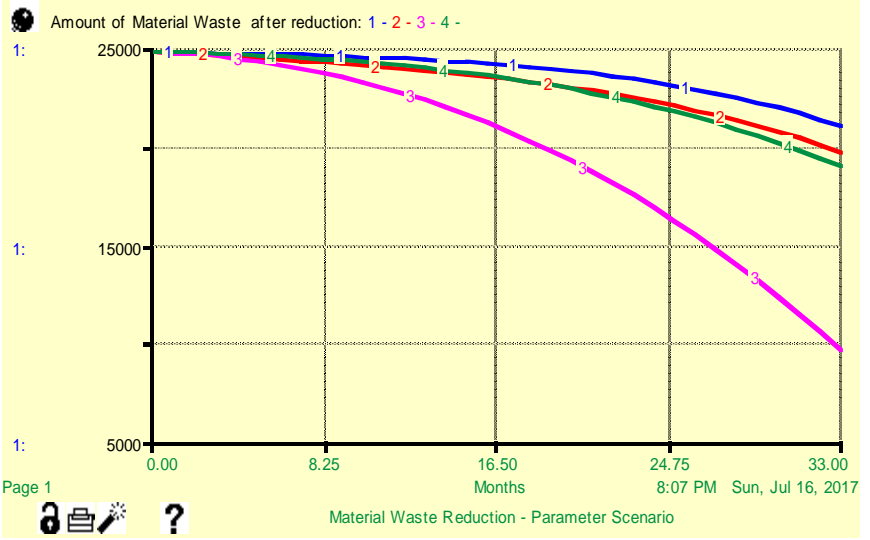

Fig. 8 Parameter scenario 
The results of the four-parameter scenarios above show that scenario-3, focusing on organizational management, given the highest reduction of material waste. Therefore, the strategy of construction companies in improving workers' waste behavior in the framework of waste material reduction can be focused on organizational management variables.

\section{CONCLUSIONS}

This research aims to offer an insight into dynamics and interrelationship of major variables in workers' waste behavior on project site that affected material waste reduction. In this research, factors influencing workers' waste behavior toward material waste reduction identified and classified under five variables. A site survey at the ongoing project and simulation through a dynamic system model conducted with these five variables.

The scenarios conducted to the base model show that organizational management variable has the greatest impact on the change of the waste behavior of construction workers. Followed by personal factors, organizational culture, and attitude variables. This is in line with other research that identifies the support from top management and clear instructions from top management are very important in implementing waste management [9]. Similarly with other research states, that the most important factor for contractors in reducing construction waste is the attitude of organizational management to the construction waste management planning at the project site [7]. The focus, priority, and commitment of the company's management

TABLE IV

MATERIAL WASTE REDUCTION FROM PARAMETER

\begin{tabular}{|c|c|c|c|c|}
\hline \multirow[b]{2}{*}{ Month } & \multicolumn{4}{|c|}{$\begin{array}{c}\text { Parameter Scenario } \\
\end{array}$} \\
\hline & $\begin{array}{l}\text { Focus on Attitude } \\
\text { (Scenario 1) }\end{array}$ & $\begin{array}{l}\text { Focus on Organizational } \\
\text { Culture (Scenario 2) }\end{array}$ & $\begin{array}{l}\text { Focus on Organizational } \\
\text { Management (Scenario 3) }\end{array}$ & $\begin{array}{l}\text { Focus on Personal } \\
\text { Factor (Scenario 4) }\end{array}$ \\
\hline 0 & $24,907.55$ & $24,907.55$ & $24,907.55$ & $24,907.55$ \\
\hline 1 & $24,890.69$ & $24,844.95$ & $24,852.51$ & $24,884.68$ \\
\hline 2 & $24,872.90$ & $24,781.80$ & $24,775.51$ & $24,856.28$ \\
\hline 3 & $24,853.93$ & $24,717.79$ & $24,676.44$ & $24,822.11$ \\
\hline 4 & $24,833.45$ & $24,652.64$ & $24,555.14$ & $24,781.90$ \\
\hline 5 & $24,811.13$ & $24,585.99$ & $24,411.45$ & $24,735.38$ \\
\hline 6 & $24,786.59$ & $24,517.48$ & $24,245.15$ & $24,682.22$ \\
\hline 7 & $24,759.44$ & $24,446.69$ & $24,056.00$ & $24,622.08$ \\
\hline 8 & $24,729.25$ & $24,373.20$ & $23,843.73$ & $24,554.61$ \\
\hline 9 & $24,695.54$ & $24,296.53$ & $23,608.02$ & $24,479.42$ \\
\hline 10 & $24,657.83$ & $24,216.19$ & $23,348.53$ & $24,396.10$ \\
\hline 11 & $24,615.59$ & $24,131.65$ & $23,064.90$ & $24,304.23$ \\
\hline 12 & $24,568.26$ & $24,042.35$ & $22,756.72$ & $24,203.38$ \\
\hline 13 & $24,515.26$ & $23,947.71$ & $22,423.56$ & $24,093.07$ \\
\hline 14 & $24,455.97$ & $23,847.11$ & $22,064.95$ & $23,972.83$ \\
\hline 15 & $24,389.75$ & $23,739.90$ & $21,680.41$ & $23,842.16$ \\
\hline 16 & $24,315.93$ & $23,625.40$ & $21,269.39$ & $23,700.57$ \\
\hline 17 & $24,233.81$ & $23,502.92$ & $20,831.35$ & $23,547.52$ \\
\hline 18 & $24,142.65$ & $23,371.71$ & $20,365.71$ & $23,382.48$ \\
\hline 19 & $24,041.69$ & $23,231.01$ & $19,871.84$ & $23,204.91$ \\
\hline 20 & $23,930.14$ & $23,080.05$ & $19,349.11$ & $23,014.24$ \\
\hline 21 & $23,807.20$ & $22,917.98$ & $18,796.83$ & $22,809.92$ \\
\hline 22 & $23,672.01$ & $22,743.98$ & $18,214.31$ & $22,591.37$ \\
\hline 23 & $23,523.71$ & $22,557.16$ & $17,600.81$ & $22,358.00$ \\
\hline 24 & $23,361.39$ & $22,356.63$ & $16,955.58$ & $22,109.22$ \\
\hline 25 & $23,184.12$ & $22,141.45$ & $16,277.82$ & $21,844.43$ \\
\hline 26 & $22,990.97$ & $21,910.68$ & $15,566.73$ & $21,563.04$ \\
\hline 27 & $22,780.94$ & $21,663.32$ & $14,821.44$ & $21,264.44$ \\
\hline 28 & $22,553.02$ & $21,398.37$ & $14,041.10$ & $20,948.02$ \\
\hline 29 & $22,306.20$ & $21,114.79$ & $13,224.81$ & $20,613.17$ \\
\hline 30 & $22,039.40$ & $20,811.53$ & $12,371.63$ & $20,259.04$ \\
\hline 31 & $21,751.53$ & $20,487.49$ & $11,480.61$ & $19,884.52$ \\
\hline 32 & $21,441.50$ & $20,141.56$ & $10,550.77$ & $19,488.50$ \\
\hline 33 (Final) & $21,108.16$ & $19,772.60$ & $9,581.11$ & $19,069.85$ \\
\hline $\begin{array}{l}\text { Material Waste } \\
\text { Reduction (ton) }\end{array}$ & $3,799.39$ & $5,134.95$ & $15,326.44$ & $5,837.70$ \\
\hline $\begin{array}{l}\text { Increment of } \\
\text { material waste } \\
\text { reduction compare } \\
\text { to the based model }\end{array}$ & $1.15 x$ & $1.55 x$ & $4.63 x$ & $1.76 x$ \\
\hline
\end{tabular}


party play an important role in the effort to change the attitude and behavior of construction workers toward material waste reduction [11].

Treatment at the sub-variables from the organizational management, such as increasing the number of training and education for all stakeholders [3], providing support at reduction efforts of material waste, providing material waste reuse and recycling facilities at the project site ([2], [24]), can be reversed by management to improve workers' waste behavior related to the material waste reduction.

The contributions of this study mainly lie in two dimensions. Firstly, the causal loop diagram that explains the interconnected relationships among major variables on workers' waste behavior in reducing material waste not only enrich the research on construction waste management, but also help project stakeholder's understanding about factors influencing their workers' waste behavior. Secondly, the established model in stock-flow diagram serves as an experimental platform for dynamically simulating the effect of different management strategies for material waste reduction over time by improving workers' waste behavior.

\section{REFERENCES}

[1] (2016) Ministry of National Development Planning / National Development Planning Dept. "Government Work Plan 2016," [Online] Available: https://www.bappenas.go.id/id/data-daninformasi-utama/publikasi/rencana-pembangunan-dan-rencana-kerjapemerintah/

[2] R. Ikau, C. Joseph, R. Tawie, "Factors influencing waste generation in the construction industry in Malaysia " Procedia - Social and Behavioral Sciences vol.234, pp. $11-18,2016$

[3] N. Udawatta, J. Zuo, K. Chiveralls, and G. Zillante, "Improving waste management in construction project: an Australian study", Resources, Conservation and Recycling, vol. 101, pp. 73-83, 2015.

[4] S. E. Sapuay, "Construction waste - potentials and constraints", Procedia Environmental Sciences vol. 35, pp. 714-722, 2016.

[5] P. Thongkamsuk, K. Sudasna, T. Tonde, "Waste generated in highrise buildings construction: A current situation in Thailand," AEDCEE, 2017, Energy Procedia, vol. 138, pp. 141 - 146.

[6] S. Nagapan, I. A. Rahman, and A. Asmi, "Factors contributing to physical and non-physical waste generation in construction industry", International Journal of Advances in Applied Sciences, vol. 1, pp. 110, 2012.

[7] M. Merino, P. Gracia and I. Azevedo, "Sustainable construction: Construction and demolition waste reconsidered", Waste Management Research, vol. 28(2), pp. 118-129, 2010.

[8] Soelistyono, "Analysis of the effect of low quality of human resources on decreasing project performance in Surabaya," M. Eng., thesis, Institute Technology Sepuluh November, Surabaya, 2014.

[9] U. Kulatunga, D. Amaratunga, R. Haigh, and R. Rameezdeen, "Attitudes and perceptions of construction workforce on construction waste in Sri Lanka", Management of Environmental Quality: An International Journal, vol. 17, pp. 57-72, 2006.

[10] Elizara, M. A. Wibowo, P. Koestalam, "Identification and analyze of influence level on waste construction management of performance," EACEF-5, 2015, Procedia Engineering, vol. 125, pp. 46 - 52.

[11] M. M. M. Teo and M. Loosemore, "A theory of waste behavior in the construction industry", Construction Management and Economics, vol. 19 (7), pp. 741-751, 2001.

[12] A. Bakshan, I. Srour, G. Chehab, "Using Bayesian network models to improve behavior towards waste management in construction projects," The 1st European and Mediterranean Structural Engineering and construction Conference, 2016, ISBN: 978-09960437-2-4, ISEC Press, Turkey.

[13] I. Ajzen, "The theory of planned behavior," Organizational Behavior and Human Decision Processes, vol. 50, pp. 179-211, 1991.

[14] J. Li, V. W. Y. Tam, J. Zuo, J. Zhu, "Designers' attitude and behaviour towards construction waste minimization by design: A study in Shenzhen, China," Resources, Conservation and Recycling, vol. 105, pp. 29-35, 2015.

[15] Q. Zhou, D. Fang and X. Wang, "A method to identify strategies for the improvement of human safety behavior by considering safety climate and personal experience," Safety Science, vol. 46, pp. 14061419,2008

[16] A. Bakshan, I. Srour, G. Chehab, M. El-Fadel and J. Karaziwan, J., "Behavioral determinants towards enhancing construction waste Management: A Bayesian Network Analysis," Resources, Conservation and Recycling, vol. 117, Part B, pp. 274-284, 2016

[17] T. L. Tudor, S. W. Barr, and A. W. Gilg, "A novel Conceptual framework for examining environmental behavior in large organizations," Environment and Behavior, vol. 40, No. 3, pp. 426450, 2008.

[18] W. Young, M. Davis, I. M. McNeill, B. Malhotra, S. Russell, K. Unsworth, and C. W. Clegg, "Changing behavior: Successful environmental programs in the workplace," Business Strategy and The Environment, vol. 24, pp. 689-703, 2015.

[19] H. Yuan, A.R. Chini, Y. Lu, Y, L. Shen, "A Dynamic model for assessing the effects of management strategies on the reduction of construction and demolition waste", Waste Management, vol.32, pp. $521-531,2012$.

[20] Z. Ding, G. Yi, V. W. Y. Tam, and T. Huang, "A system dynamicsbased environmental performance simulation of construction waste reduction management in China", Waste Management, vol. 51, pp. 130-141, 2016.

[21] Y.Barlas, "Format aspect of model validity and validation in system dynamic", System Dynamics Review, vol. 12, number. 3, pp. 183 210, 1996.

[22] H. Qudrat-Ullah, and B. S. Seong, "How to do structural validity of a system dynamics type simulation model: The case of an energy policy model," Energy Policy, vol. 38 (5), pp. 2216-2224, 2010.

[23] F. Fahruddin, "Prediction Model of Cost Performance And Time Construction Projects using Hybrid-Based Bayesian Belief Networks - Markov Chain," PhD, thesis, Institute Technology Sepuluh November, Surabaya, 2016

[24] C. S. Poon, A. T. W. Yu, S. C. See, E. Cheung, "Minimizing demolition wastes in Hong Kong public housing projects," Construction Management and Economics, vol.22, pp. 799 - 805, 2004. 